\title{
Live Meanings
}

\section{Paul Dekker*}

A notion of 'Live Meanings' serves to relativize the ambitions of formal semantics and to strictly maintain a principle of compositionality; this enables one to enjoy, not deny, findings of the contextualists-as well as those of cognitive or conceptual semanticists. The paper can be taken to argue for a cohabitation of the distinguished disciplines.

\section{Introduction}

An age old incompatibility is felt between those who advocate the philosophical analysis of language versus those who plead for a logical one, and between those who favour or practice cognitive versus those who adopt model-theoretic theories of meaning. The controversies appear in various guises, in the philosophy of language, in linguistics, and in the cognitive sciences, and show up in debates under the headings of contextualism and compositionality, and in debates on the benefits and misfits of cognitive or conceptual, and truth-conditional semantics.

It seems to me that the antagonies can be traced back to an unrealistic preconception of meaning, and, paired to it, a misapprehension of the results obtained in the area of formal semantics. The preconception and misapprehension are shared by opponents as well as proponents of formal semantics. The basic, and I think mistaken, or wrongly appreciated, idea is that there are such things as meanings, and that semantics consists in the intellectual endeavour of finding out what they are and studying them. In his overview of "Theories of Meaning" in the Stanford Encyclopedia of Philosophy, Jeff Speaks recently formulated the task of

\footnotetext{
I would like to thank an anonymous reviewer, Peter Bosch, Martin Stokhof, Ken Turner and Seyed Mohammad Yarandi for inspiring comments and discussion.
} 
the philosopher of language interested in semantics as follows: "her job is [to] say what different sorts of meanings expressions of a given language have, and which expressions have which meanings" (Speaks 2010/4). Martin Stokhof speaks of an 'Availability Assumption', "which holds that meanings are available independently of their being expressed, in a natural language or in a formal language. Only on that assumption does it make sense to (...) use one expression as a formal representation of the meaning of another. And especially the latter is the daily work of the formal semanticist" (Stokhof 2013, p. 210). Actually, I don't think these are proper qualifications of the findings of formal semanticists, even if these are endorsed by those themselves.

I believe it does not make any real sense to talk, out of the blue, of "the meaning of an expression", or believe in the existence of such things, without any very specific context or theory appended-almost obligatorily a context or theory that defines the term 'meaning'. (More radically, perhaps, I also do not believe in the existence of categories of expressions, of sentences, or names, without such qualification, but this matter goes beyond the purposes of the present paper.) Yet, like I said, such a conception of meaning is endorsed by proponents as well as opponents of the formal semantic enterprise. François Recanati speaks of "context-independent meanings of our words" which can be "contextualized" and "modulated" (Recanati 2004, p. 131); Jerry Fodor starts an argument against formal semantics by "taking for granted that either sentences mean what they do because they express the thoughts that they do, or vice versa (whatever, exactly, vice versa comes to here.)" (Fodor 2001, p. 2); William Croft presents the "pairing of a complex grammatical structure with its meaning" as a basic form and the fundamental principle behind construction grammar (Croft 2010, p. 463).

Without the intention to oppose or ridicule, colloquial or academic, discourse about meanings, these discourses can be taken to involve profoundly contextual and abstract theoretical uses of the term 'meaning'. But what are meanings, if they do not exist? Figuratively speaking I would like to put it thus. One can, at any moment, make any arbitrary distinction -cut the pie this way or another- and then we have what is on the one side of the distinction, and what is on the other. The two then are possible meanings, without any assumed characteristics other than that of being distinct from one another. In practice, but also in theory, we continuously make, and mask, such kinds of distinctions, and the very practice of doing so is embedded in a publicly conceptualized environment, partly governed by conventional and 


\section{Live Meanings}

intentional principles. Aligning with (Quine 1948) and (Wittgenstein 1953), we may recognize human verbal, or linguistic, behavior as meaningful, without thereby postulating a realm of meanings, by conceiving of it as embedded in such practices.

Typically, verbal, or linguistic, practices have all kinds of structural characteristics which semanticists (and linguists, psychologists and philosophers in general) may want to lay bare, even though unavoidably abstractly and sketchily. If need be, we can distinguish various dimensions of meaningfulness, e.g., a realistic or representational one, a cognitive or conceptual one, or a social and practical one. Various, theoretically possible, notions of meaning may emerge once one focuses on one of these dimensions of meaning, and fixes or ignores others. Certain types of expressions, or items recognized as of certain types of expressions, then can be taken to stand for certain categories of beings, thus rendering beings so-characterized as the possible meanings of expressions so-typed; or certain conventional or functional categories of linguistic items, or items thus identified, can be associated with types of cognitive or social acts. Whatever the typologies are, they may each induce their own ontology, and help to uncover or state relatively systematic distinctions and generalizations that appear significant along that dimension of meaning. Notice, however, that nowhere in the statement or observation of such general characterizations need it be assumed that purported 'meanings' are, or are like, 'real' meanings. A good reason being that, I think, it is highly inappropriate to speak of 'real meanings' in the first place. One may best think of these 'meanings', so-called, as mere artefacts of theories that help one lay bare structural meaningful aspects of the use of natural language.

In the next section I will discuss how this reserved attitude towards meaning bears on contextualist insights, and more in particular on the conclusions that can be drawn from them. These insights will be taken to motivate an arguably intuitive understanding of the principle of compositionality-a principle one can take to be Iphigenia's heart and the Achilles' heel of formal semantics. This moderate, here called 'live', understanding of the principle initiates a fresh look at a series of cases which seem to escape a rigid understanding of the principle. These cases can or have been taken to support contextualist arguments against compositionality. As we will see, however, they, instead, can be taken to favour the principle upon its proper, live, understanding; consequently, they can be seen to speak in favour of formal semantics more in general. The picture that results from these considerations 
finally provides an outlook on the semantic landscape as cohabitated by various, preferably collaborative, disciplines.

\section{Contextualism and Compositionality}

The formal study of meaning in natural language is seriously devoted to the Fregean principle of compositionality. This principle can be found at work in Frege's writings (e.g., Frege 1892), and although it is not stated as such by Gottlob Frege himself, it can be formulated as follows. "The meaning of an expression is a function of the meanings of its parts and their mode of composition." (The Principle of Compositionality, PoC.) The intuitive idea should be familiar. If an expression is syntactically built up in a certain way from meaningful constituent expressions, then the meaning of the whole can be taken to depend on, be defined by, the meanings of these constituent expressions. (And, it needs to be added, by the interpretation of the specific way in which these constituent expressions have been combined into the whole.) This principle, in this or one other formulation, shows up in the vast body of 20th century work on logic, language and computation. (For a solid, general overview, see Janssen 1997, Partee 2004.) The principle allows for a formal explanation of the fact that finite language users may be able to create, use and understand a possibly infinite number of expressions so as to express a possibly infinite number of meanings.

The principle can be conceived of, with reason, the heart and heel of formal semantics. The heart, because it portrays interpretation as a most rudimentary and principled formal mapping between two recursive structures, as a homomorphism of a given syntactic algebra to an algebra of meanings, independently specified (Montague 1974, Janssen 1986). The heel, precisely because it has to assume this algebra of meanings, and, because, given its rigid formal specification, it does not seem to allow for modulations in this mapping. An old but fairly common conception of a so-called 'minimalist' formal semantics does allow for pragmatic modifications of semantic meanings, but only after these are compositionally assigned to analyzed syntactic structures (Borg 2004, Cappelen \& Lepore 2005).

As I said at the start of this paper, I do not believe in a realm of independently existing meanings, and it is at this point that the compositionality principle can be questioned, and revaluated, as we will see. The principle has been challenged in the first place, from a 'contextualist' angle. A natural challenge to the principle 


\section{Live Meanings}

springs from the observation that meaning is generally determined by parameters of interpretation, other than those provided by syntactic clues, parameters which can probably not better be characterized than 'contextual'. (Hence, the label 'contextualism'.) In the philosophy of language it is generally observed, often following the lead of the later Wittgenstein (Wittgenstein 1953), that the context of the use of language plays a pervasive role in its interpretation, and this to such an extent that it hardly deserves the effort any longer to try and systematically characterize meanings of natural language expressions without paying due attention to these contextual aspects.

The contextual impact on meaning and interpretation has been subsumed under various labels. To name a few, there is pragmatic enrichment, argument saturation, domain restriction, predicate loosening, semantic coercion, deferred reference, and what have you. Generalizing somewhat crudely, one may bring them all under the label of 'modulations' of meaning (Recanati 2004). It can be attested that the various types of modulation indeed affect all acknowledged types of semantic phenomena, reference, predication, quantification, and other semantic constructions alike. It will not do to repeat all the contextualist examples that have been presented, as they are many and they are also probably fairly well-known.

François Recanati adequately summarizes the general findings, and Emma Borg resumes what seems to be a common conclusion:

Contextualism holds that what is said depends on the context of utterance. The evidence in favor of contextualism is provided by indefinitely many examples in which the same sentence, which does not seem to be ambiguous, is used in different contexts to say different things (Recanati 1994, p. 164). According to these philosophers, sentences can never express complete propositions independent of context, however explicit speakers try to be. In other words, content is always under-determined by the linguistic material (Recanati 2006, p. 23). Contextualism ascribes to modulation a form of necessity which makes it ineliminable. Without contextual modulation, no proposition could be expressed-that is the gist of contextualism (Recanati 2005, p. 179-80).

These days, the natural descendent of the formal approach, known as minimalism, has been consigned to the margins: not everyone rejects minimalism, but lots of people do. Minimalism is rejected in favour of contextualism: roughly, the idea that pragmatic effects are endemic throughout truth-evaluable semantic content (Borg 2007, p. 339). 
There are few indeed that contest the contextualist's observations, but there are also those who do not consider these findings a threat for the formal semanticist. (E.g., Herman Cappelen and Ernest Lepore, Emma Borg, Peter Pagin and Jeff Pelletier, and Peter Lasersohn.) More particularly, Pagin and Pelletier 2007 and Lasersohn 2012 have shown the contextualist observations to be consistent with a compositional rendering of the syntax-semantics interface. The first develop a classical compositional architecture of interpretation which provides room for the outcomes of pragmatic modulations within the composition of meaning. They propose a compositional syntax/semantics architecture which allows, for any analyzed sentence, modulation of every constituent of its construction-tree and of the corresponding meaning-tree. Such an architecture suits the theoretical goals very well, but also, I think, does not reach to the heart of the matter, which is where the principle of compositionality is both valuable and vulnerable. Pagin and Pelletier still build on a fixed semantic algebra, start off from given meanings of atomic constituent expressions, and then allow for virtually any assignment of meanings of compound constructions on the basis of no matter what meanings of their constituent expressions. Now I do agree that in principle any expression, however constructed, can be assigned any meaning. (Who could possibly be in charge of excluding any such meaning assignment?) But in a formal logical space of postulated set-theoretical meanings, a systematic interpretation procedure which is so open may strike one as vacuous.

Lasersohn sketches a compositional assignment of contents which also takes contextual, 'radical pragmatic', effects on the interpretation of constituent expressions to heart. His proposal relates to specific occasions of use, and employs, e.g., what certain parts of a sentence are "used to talk about" in a given context, and allows these to enter into a compositional meaning assignment. Lasersohn himself is deliberately pretty open about what goes under the heading of "what you are talking about" and mentions, e.g., speaker's reference and semantic reference, and "perhaps other kinds of "talking about"”. As we will see, Lasersohn's proposal is actually very close in spirit to the one I am about to propose, but I hope to formulate mine in both a more radical and a more principled manner.

To the extent that it makes sense to talk about meanings in the first place, I think the meaning of an expression cannot but simply be whatever meaning it has on its occasion of use. Let us label this the 'live meaning' of the expression on its occasion of use. A live meaning can, indeed, be anything, but it should 
obviously be tied to such an occasion of use, and be live and determined there. Notice that this notion does not deny, or threaten, or even empty, the principle of compositionality, as essentially also Lasersohn observed. For, the meaning of a compound expression, on its occasion of use, can be taken to be determined by whatever are the meanings of its constituent expressions, on that occasion of use. We can capture these observations by slightly reformulating the principle of compositionality as follows.

Live Principle of Compositionality (LPoC) The live meaning of a compound expression is a function of the live meanings of its parts and their live mode of composition.

I claim that this formulation of the principle preserves its original intent, in keeping with how it can be meant to apply. Let me elaborate somewhat on the present statement of the principle, in particular on the adjective 'live' employed here.

First, if one chooses to read the adjective as 'real,' the principle as stated is just an emphatic statement of the original principle. Thus understood, assuming real meanings and real composition of meaning, the live principle of compositionality states what formal semanticists and logicians have been working with for years. Second, the live meaning of an expression when used on a certain occasion may serve to distinguish it from the live meaning of that expression when used on another occasion. (Obviously, this raises the question of how one can identify the two uses as uses of one and the same expression. As indicated above, this is a very serious question, but not one I will go into in this paper.) This, as a matter of fact, is where the contextualist findings fit in.

If one assumes or believes that expressions are associated with meanings independent of their use -ideally, so-called 'literal' meanings- still one needs to acknowledge that the very same expression can be used in a whole variety of different ways, with different meanings associated. The point here is that upon the LPoC it is the 'deviant', or better, 'instant', meaning of the expression on that occasion of use, that contributes to the meaning of the whole in which that expression occurs as a constituent. Otherwise, I take it, there would be no sense in saying that the expression had occurred with a non-literal meaning. This seems to be fairly obvious. If, on the other hand, one does not believe in such things as literal meanings, then, I believe, the live meanings of expressions are the only things that are left to talk about, if, that is, one wants to make some sense of the talk of 'the meanings of expressions' at all. 
This brings me to the third point, the question, of course, what these live meanings are? The 'live meanings' of expressions are here understood to be their actual interpretations in their specific contexts of use. They are what the interlocutors, and a suitably informed observer, can agree upon as to what the expressions mean, in those contexts of use, and they are assumed to be public, and determinate, in the context, in principle. (The contexts, as well, are supposed to provide the background relative to which they are determinate.) If any of this fails, if assumptions are not warranted, or not intended, or if possible interpretations don't make sense, then one might judge there is no live interpretation, or another suitable one has to be constructed. The point is that if, or once, such interpretations remain unquestioned, they are determinate (enough) to enter, indeed, into the compositions of (live) meanings. Obviously, this leaves no need nor room for further contextualist qualifications, because upon the present picture the meanings we are dealing with, and which enter the composition process, are contextually completely saturated.

In the next section I will discuss some cases in which one can imagine such construction of meanings at work. (These are fabricated cases, but not fabricated for the present purposes.) Contextualists, or at least some of them, have taken such examples to motivate contextualism, cast doubt on the principle of compositionality and, thus, disqualify a formal semantic approach to meaning. But actually, as I will argue, quite a few, if not all, examples are understood best precisely in terms of the principle of compositionality, upon its live understanding, and thus supply support for compositionality, and, by implication, for formal semantics.

\section{The Performance of Meaning}

Upon the live understanding of the principle of compositionality, the building blocks in the composition of live meaning on a certain occasion of use are the live meanings of the participating constituent expressions-not any other meanings that these constituent expressions may have on other occasions. This may look like a trivial observation, but actually it is not, as it goes against the ways in which the principle of compositionality has been assumed to apply in the analysis of natural language. Our discussion of the following five cases is meant to show that, not only live meanings are actively 'present' on the relevant occasions of use, but also that 'past' meanings are not. The cases, together with a few others, are discussed somewhat more extensively in (Dekker 2014). [Whatever are 'past meanings' is left 


\section{Live Meanings}

to the reader. She may think of them as 'literal meanings' -if she can make sense of that term- once these have been superseded by live interpretations; or, otherwise, as just whatever other live meaning the relevant expressions have been associated with before their present use. Choosing the latter option would of course come close to agreeing with the conception of interpretation advocated in this paper.]

Case 1 (The Jones's) [The first case arises in a reaction from Saul Kripke on an ambiguity that Keith Donnellan seems to have propagated.]

Two people see Smith in the distance and mistake him for Jones. They have a brief colloquy:

(1) "What is Jones doing?"

"Raking the leaves."

"Jones," in the common language of both, is a name of Jones; it never names Smith.

Yet, in some sense, on this occasion, clearly both participants in the dialogue have referred to Smith, and the second participant has said something true about the man he referred to if and only if Smith was raking the leaves (whether or not Jones was). In the example above, Jones, the man named by the name, is the semantic referent. Smith is the speaker's referent, the correct answer to the question, "To whom were you referring?” (Kripke 1979, p. 14/15)

Kripke acts in this case as a suitably informed observer, and we can imagine him intruding into the colloquy saying:

(2) That is true, but he is not Jones.

He would, thus, indicate, that he picked up an understanding of (1) as being about Smith, refer back to him with his own use of the pronoun 'he', and re-establish the past, 'official', interpretation of 'Jones' by reusing the name 'Jones'. Alternatively, assuming that the real Jones is as a matter of fact not raking the leaves, Kripke might have interjected with:

(3) That is false, he is not Jones.

What would be false, then, is that Jones is raking the leaves, so the statement that gets corrected is not that Smith is raking the leaves, which is obvious, but the statement that Jones is raking the leaves. With (3) Kripke would thus show that he actually construes (1) as about Jones, at the same time realizing, of course, that the interlocutors are discussing Smith. This is apparent from his use of the pronoun 'he' in (3), which demonstratively refers to the guy who is raking the leaves, Smith. 
Upon this understanding, Kripke might as well have pointed out, slightly wittily:

(4) That is false, he is not him.

If replying thus, 'he' would again have been used as a demonstrative referring to Smith, actually present, and the pronoun 'him' could be conceived to be coreferential with the term 'Jones' used by the first speaker, and according to Kripke's own picture of the common language. So there is an amalgam of referents here: the person actually present, Smith, who figures as the so-called speaker's referent, and Jones himself, which can be supposed to be called by his name.

Interestingly, it appears to be very difficult, if not impossible, to construe (1) as a true statement-about Smith, that is- while at the same taking 'Jones' to involve Jones.

(5) ? True, but he is not him.

The confirmation indicates that Kripke construes (1) as being about Smith, which then is his live understanding of 'Jones', and somehow he cannot then pick up on this as involving the real Jones, in order to select him, Jones, as a referent for the second pronoun 'him' in (5). I take it that a reply with (5) indeed sounds quite bizarre. This is to say, I take it, that 'Jones' may have a semantic referent, and a speaker's referent, which can be distinct, but when the two are different, only one meaning can be live.

Case 2 (The Ham Sandwiches) [This is also a famous case, brought to us by Geoffrey Nunberg.]

For example, a restaurant waiter going off duty might remind his replacement:

(6) The ham sandwich is sitting at table 20.

(Nunberg 1979, p. 149)

It is clear to most of us that the restaurant waiter, by uttering (6), refers to a person, not a ham sandwich, so that in our terms the live meaning of 'the ham sandwich' is someone who, e.g., orders, or has been served, a ham sandwich; it is not the ham sandwich. Thus, later in the scenario, one can imagine the waiter, still there, to follow up with, for instance, (7):

(7) The ham sandwich wants to pay. He is in a hurry.

Once the phrase 'the ham sandwich' is understood thus, as referring to a person, it seems awkward to suppose that it still is about ham sandwiches. A statement like the following therefore appears to be too overly underspecified. 
(8) 'The ham sandwich wants to pay for it.

Of course, the pronoun 'it' can, as always, be used to point at anything that makes sense, for instance, at whatever was served to him, or at whatever was done to him. I do not, however, succeed in taking it to refer to-that is what it would be-the ham sandwich by means of which the waiter just focused the hearer's attention to the person who ordered it.

The replacement in the restaurant might of course be unfamiliar with the deferred use of 'ham sandwich' in (7). After asking (9), it can thus be illuminating if the waiter replies with (10):

(9) Who wants to pay?

(10) The ham sandwich. The ham sandwich is the person who ordered the ham sandwich.

It seems pretty unilluminating, on the other hand, if (9) were countered by (11):

(11) The ham sandwich. The ham sandwich is the person who ordered it.

Upon hearing (11) the replacement probably wonders 'the person who ordered what?' He may be able to figure out, upon reflection, that it should be the person who ordered the ham sandwich. But this ham sandwich [digestible] is not as lively present as the ham sandwich [person] referred to by means of 'the ham sandwich' in (7).

Nunberg later observes that it may not so much be the whole (referential) noun phrase that gets a 'deferred meaning', or whose live meaning is at stake, but, rather, the (predicative) noun. “(...) there are a number of reasons for concluding that the transfer here takes place on the common noun meaning-that is, that this is a case of meaning transfer, rather than reference transfer. (...) the transfer actually takes place at the level of the common noun, which contributes only a property of persons (...)" (Nunberg 1995, p. 115-6). If the restaurant's replacement appears to be familiar with the indicated use, he might also wonder about (7) and reply with (12):

(7) The ham sandwich wants to pay. He is in a hurry.

(12) There are three of them. Which one wants to pay?

It, then, seems perfectly appropriate to answer his question with (13), but a reply with (14) appears to be pretty odd again.

(13) The one that stumbled in the toilet.

(14) ? The one that fell on the floor in the kitchen. 
Apparently, in the cases above the noun 'ham sandwich' is interpreted as a predicate applying to persons, not digestibles. And it is the first, not the second, interpretation that is most likely alive. And the one that is live is present, and the other one is not. Case 3 (The Philosophers) [The third case is as a matter of fact a whole array of cases.] Consider the following sentence.

(15) Few philosophers are linguists.

It seems to be common opinion in the semantics literature that quantified structures of the form $\operatorname{DET}(A, B)$-where $D E T$ is a determiner phrase, and $A$ a nominal or set denoting expression, and $B$ a verbal one- presuppose a domain of $A$ 's and contribute discourse referents $A$ 's who are $B$, and possibly $A$ 's who are not $B$. There is also quite some consensus that quantified noun phrases generally serve to quantify over contextually restricted domains of quantification, and, of course, that nouns like 'philosophers' can be used to classify philosophers in various ways: as professional philosophers, as persons displaying a certain kind of philosophical behavior, persons otherwise distinguished as philosopher-like, etc.

Independent of any analysis of presupposition, contextually restricted quantification, and discourse reference, one thing seems to be entirely clear. If the term 'philosopher' is used to characterize or distinguish individuals in one of these ways, relative to some contextually given domain of quantification, then the presupposition is that there is a domain of philosophers classified precisely that way in that domain of quantification; also, if a discourse referent is introduced for the philosophers who are linguists, then this discourse referent involves all those who classify as philosophers in the way in which the term 'philosopher' was understood, or intended in the first place, and in the contextually given domain of quantification. (And, likewise, for them being 'linguists' in the way in which few of them were said to be linguists.)

Actually, it seems very hard to explain how this could not be the case. Let me give it a try. No sense can be made of an, almost inconceivable, use of (15), according to which few of a contextually salient group of philosophically behaving children practice linguistics, while it presupposes a domain of professional philosophers, and sets up a discourse referent for a world-wide group of professional philosophers and linguists. Like I said, it is very difficult to explain what I think is excluded, which is that a statement made by (15), its presupposition, and its discourse anaphoric potential, relate to different possible interpretations of the term. Upon any sensible 


\section{Live Meanings}

understanding of a use of (15) only one interpretation is the live one, although many other interpretations are possible, yet these are claimed to simply be not present. Not alternative ones, not even, literal ones-if any.

The very point is perhaps illustrated more concisely by the following two examples. Everybody, except maybe certain formal semanticists, can make sense of (16).

(16) You have philosophers and philosophers.

Two uses of one and the same term easily invoke-here invite-a different live interpretation. One use of it doesn't do so, or so it seems. At least I am unable to state what (16) can be taken to say, by using (17):

(17) ?You have philosophers and them (they themselves).

If a live, 'secondary', interpretation of the first use of 'philosophers' in (16) were derivative on a 'primary', 'literary', meaning of the term, then one should be able to say what (16) says by using (17). But, like I said, I do not succeed in making this work.

Case 4 (The Presidential Elections) [This case involves a factual state of affairs.]

In 1969, January 20-th, Richard Nixon succeeded Lyndon B. Johnson as the president of the United States, so that after eight years of Democratic rule (with John

F. Kennedy and Johnson), an eight year period of Republican rule started (with Nixon and Gerald Ford).

One could have described this situation, correctly, if one had uttered, in 1969:

(18) For the last eight years the president was a Democrat and the next eight years he will be a Republican.

Example (18) could have been used, in 1969, to state something true, if the noun phrase 'the president' was rendered, or read, as whoever has been residing in the Oval Office over a certain stretch of time. On this reading it would merely serve to sum up the outcomes of the presidential elections over some sixteen years. Alternatively, example (18) could have been rendered as being about the actual president, in 1969, Johnson. On this reading it would state that Johnson had been Democrat the past eight years, and, surprisingly, and falsely I assume, would have turned out Republican the next eight years.

Theoretically one might want to try and use (18) to state that we had had 8 years of Democratic rule, and that Johnson now will be Republican the next 8 years, for the president [whoever it was] was democratic the last 8 years, and the president [the actual one now] will be republican the next 8 years. Formally 
there is no problem in stating such an interpretation. However, it is an extremely unlikely-many will say impossible-way of construing an understanding of 'the president' in example (18).

It is assumed that the pronoun 'he' in the second sentence of example (18) picks up the president from the first sentence, and it should intuitively do so under the interpretation that 'the president' had there-i.e., its live meaning. Thus, if 'the president' would have been read as Johnson, then so would 'he', and if 'the president' would have been read as whoever, in any of these sixteen years, had won and would win the elections, then so would 'he' be read. A 'mixed' interpretation which would enable the interpretation of the phrase 'the president' to work out referential on its use relative to the coming eight years, while it applied in an attributive way relative to the previous eight years, does not appear to be a viable live interpretation at all-it has no chance of survival.

Case 5 (The Brothers Karamazov) [The last case involves the writing and reading of The Brothers Karamazov.]

Although Dostoyevsky began his first notes for The Brothers Karamazov in April 1878, he had written several unfinished works years earlier. Dostoyevsky spent nearly two years writing The Brothers Karamazov, which was published as a serial in The Russian Messenger and completed in November 1880.

(http://en.wikipedia.org/wiki/The_Brothers_Karamazov)

One may conclude:

(19) Dostoyevsky began The Brothers Karamazov in 1878. He finished it in 1880. As a matter of fact, I got a copy of The Brothers Karamazov from my grandmother early in the winter of 1977, and I read it over the Christmas break. It is true to say that:

(20) I began the book by the end of 1977, and finished it ten days later.

Books are written, published, read, started, and completed. As can be seen from the examples (19) and (20), the noun phrase 'The Brothers Karamazov' can be used to denote the event of writing the book, which Dostoyevsky started in 1878, and an event of reading it, which I for instance completed in 1978. Interestingly, it cannot be used to denote both events at the same time. It appears to be particularly odd to conclude, from (19) and (20) that.

(21) ?Dostoyevsky began The Brothers Karamazov in 1878. I finished it in 1978. 


\section{Live Meanings}

What I read is what Dostoyevsky wrote, The Brothers Karamazov. So what he began in 1878 is what I finished in 1978. Or not? What he began was writing The Brothers Karamazov, and what I finished was reading it, so not the writing of it. So what Dostoyevsky began in 1878 is not what I finished in 1978, and upon the most likely understanding of (19) and (20), it does not allow one to conclude to (21).

We see that once the book is 'coerced' into an event, it is the event, and no longer the book, that is present. Stated thus, this might actually be surprising. Not so, however, upon our formulation of what goes on. When the live interpretation of 'The Brothers Karamazov' is an event, it is not a book, and this is a very trivial observation, of course.

These five cases are meant to illustrate, not so much the fact (taken as obvious) that the interpretation of constituent expressions of compound constructions can be heavily context dependent, but that these live interpretations contribute to, or determine, the (live) meanings of the whole of these expressions. As a matter of fact, once we drop the assumption that meanings are non-contextually givens, and allow live meanings to enter the interpretative architecture, one can clearly see the principle of compositionality at work in our actual understanding of natural language. The findings of the present section are, thus, in complete agreement with Lasersohn's conclusion: “(...) far from being problematic for compositionality, contextual variation in interpretation is precisely what rescues the claim that interpretation is compositionally assigned from apparent counterexamples" (Lasersohn 2012, p. 188).

In the statement of the LPoC mention was made also of the 'live mode of composition' and I want to conclude this section with some tentative reflections on this.

Linguists and philosophers with a proper interest in language alike share an interest in so-called "structural ambiguities", apparently or potentially present in almost every natural language sentence. The phenomenon of a structural ambiguity can be tuned down, in the present terminology, to the possibility of having one, rather than another, live mode of composition of a given utterance. We intend and interpret a string like, e.g., "old men and women", as if it were constructed by first modifying the noun "men" by the adjective "old", and then conjoining the result with the noun "women", or, alternatively, as if it were obtained by modifying the conjunction of the two nouns by the adjective. The string itself, however, is appropriately characterized as consisting of three linearly ordered words, and 
does not itself display any structure. It is a matter of theoretical idealisation (mythification, or metaphor, if one wants), when we speak of the string of three words having two or more readings, out of which we pick one. Instead, there is only one, according to the rules currently in charge. Not the string, but its occurrence, is associated with an analysis, and then the LPoC tends to dictate only one analysis, reading, interpretation.

Analogous observations, and more subtle distinctions, can be made regarding the ways in which nouns and noun phrases are combined in possessive constructions such as "Michelle's portrait", "Derek's omelet", "Tony's roots", "the back of the car", "the construction of the city" and "the start of the play". Given the many various ways in which nouns can be, thus, taken to be combined, it appears hard, even unrealistic, to imagine a grammar handing out the theoretical combinatory possibilities, from which a context should help us pick one. Instead, we assume a felicitous use of such combinations to yield the proper one, which, if not contextually questioned, decides on the interpretation, or meaning of the whole. If the ensuing conceptual construction, or the associated truth conditions, conflict with other indicators in the context, then, apparently, we have misconstrued the complex. Such, however, would not mean that the grammar has failed.

Proper, live, compositions also seem to be required when we employ or face nounnoun compounds, such as "book shelf", "bicycle pump", "kitchen knife", "university hospital" and "machine learning". Here, even more, we face a theoretical wealth of combinatory possibilities, while on their regular, that is unproblematic, occurrences, we only use one. There is of course the obvious, decontextualized question, "which one-or which of the ones?” And, again, the only, theoretically uninformative, but correct, answer is "the right one".

The possible modes of composition, and the distinctions that can be made among them, are theoretically intriguing, but they are mentioned here only to point out what the live principle of compositionality apparently implies: that we employ modes of composition according to the rules assumed currently in charge, that is, 'live'. Again, if one chooses to assume, or live by, one rigid, stipulative, grammar, the live principle of compositionality only dictates compositions of (live) meanings according to the rules of grammar, as it is usually taken to dictate. Allowing, more flexibly, for, theoretically unconstrained, but contextually induced modes of composition, it seems we can naturally accommodate the heterogeneity of natural language generation and interpretation. I will not go into the implications of this 
notion of live modes of composition any further here, and leave it as a subject for further exploration and discussion elsewhere.

\section{Context and Conceptual Space}

I take it that the principle of compositionality can be maintained with regard to any contextualist findings, and possibly contrary to some contextualist conclusions. It may have occurred to the reader that the preceding discussion has been stated in all kinds of semantic terms, like meanings, interpretations, speaker's reference, presupposition, coercion, etc. Obviously, the principle of compositionality, also on its 'live' formulation or understanding, does invoke the concept of (live) meanings of constituent expressions, and refers to or quantifies over them. The discussion, however, should not be taken to build on a given category of meanings, as repudiated by Quine and ourselves. "I remain free to maintain that the fact that a given linguistic utterance is meaningful (or significant, as I prefer to say so as not to invite hypostasis of meanings as entities) is an ultimate and irreducible matter of fact; or, I may undertake to analyze it in terms directly of what people do in the presence of the linguistic utterance in question and other utterances similar to it" (Quine 1948, p. 30-1). All semantic vocabulary is intended to reflect our intuitive and everyday understanding of 'significant' verbal behavior. All we suppose is that, relative to the envisaged contexts, the semantically relevant distinctions can be made, intelligible to us, here, and to the envisaged participants.

It must be submitted that indeed, if one wants to give a formal characterization of observations of the kind indicated above, which after all constitutes an aim of the formal semantic enterprise, this implies that such relevant distinctions get formalized, too. If different occurrences of one and the same term are associated with different live meanings, they have to be formally distinguished. Such is expedient in order to keep the compositional architecture formally transparent, but it does delegate quite some work to the mapping from concrete utterances to 'logical forms', however understood. E.g., an utterance, sensibly interpreted, of 'All philosophers are philosophers' will presumably have to be mapped to something like the formally transparent ' $\forall x\left(P x \rightarrow P^{\prime} x\right)$ '. We can, however, leave the required mappings to the formal linguists, and to those who seek to apply the formal semantic insights and results. Such is not our main concern here though. 
More relevant to the present discussion is the observation, directly taken from the contextualists, that live meanings are determined in a context of use. We have to be careful when using the term 'determined' here though. I emphatically want to abstain from the idea that this involves the existence of meanings, which get subsequently 'determined' ('specified', ...) in a context of use. I think that on any successful or unproblematic occasion of use, these so-called meanings are there, completely, and as determinate as required and defined by the context. The idea is that, in principle, we can all engage in an assessment of the relevant distinctions, in the context, and of the relevant distinctions imported by a specific utterance in that context. The only formal, or philosophical, requirement is that these distinctions are public.

Such a context can be conceived of as a public space, publicly accessible, and we evaluate (interpret, ...) utterances as acts in such a space. This may seem like a vacuous truism, but it does, or should, help in qualifying the semantic abstractions made from those contexts. At the end of the day, the 'live meanings' that we talk about are eventually not the instantiations of (suitable) abstractions, but the abstractions are artefacts of a theory modeling interesting, structural, features of specific acts in the first place meaningfully performed in a public space. One ought to just realize that all of the discussion in the preceding section-and probably all sensible work discussed under the heading of semantics, only makes sense if the reader interprets or assesses it against the background of any context of use-most often an imaginary one, but at least an (imagined) publicly accessible context of use.

It may be noticed that there is nothing that prevents us from thinking of this public space as a conceptual space. On the contrary: much discussion in linguistics and semantics is apparently conceptual. After all, there does not seem to be any ground for anyone to make a fundamental or categorical distinction between the real and the conceptual, or, better, between things that we know only really, but not conceptually, and those that are by their nature only conceptual, but not real. But then it is only a small step to recognize that the public space where we locate live meanings, can be very much of the kinds proposed in various systems of conceptual or cognitive semantics. Mental spaces, frames, conceptual space, discourse representation structures if one wants, can all be taken to present their own ways of formulating or modeling cognitively significant aspects of the very same public space. 


\section{Live Meanings}

That a public space is considered a conceptual space may not come as a surprise to many. That the kind of conceptual space we are interested in here is public, may also need no argument, but it may have to be emphasized. Mental spaces, frames, their constituents, conceptual categories, prototypes, semantic features and relations, are postulated in a public, theoretical, language, and described as generally accessible and publicly available objects, sets, or other constructs with a consensual status in the various theories. They are general coin and a common good.

I propose that frames provide the fundamental representation of knowledge in human cognition. I assume that frames represent all types of categories, including categories for animates, objects, locations, physical events, mental events, and so forth (Barsalou 1992, p. 21/9). Mental spaces are very partial assemblies constructed as we think and talk for purposes of local understanding (Fauconnier 2010, p. 351). [T] he notion of a construction (...) is a uniform model for the representation of all grammatical knowledge-syntax, morphology, and lexicon (Croft 2010, p. 463). An expression's content consists in a set of cognitive domains. (...) These are not themselves concepts but irreducible realms of experience within which conception can emerge (Langacker 2010, p. 98).

Such public conceptions may of course serve as a challenge, but only rarely picked up, it seems.

Prima facie, this appears to be an enigma for the cognitive approach to semantics: meanings are things that are common to the language users. (...) The idea is that the conceptual structures of different individuals will become attuned to each other, otherwise linguistic communication will break down. Thus, for practical purposes, cognitive linguists often write as if every (adult) speaker of a language is enodowed with the same conceptual structure (Gärdenfors 2000, p. 155).

It seems that proceeding on that, practical, assumption, and assuming that linguistic communication factually does not break down, we do well in declaring conceptual space public. Gärdenfors' conception of conceptual spaces is presented as an attempt to make sense, after all, of the cognitive structures as purely individual cognitive structures. "One advantage, in contrast to cognitive semantics, is that we need not assume that the interlocutors share identical mental spaces" (Warglien \& Gärdenfors 2013, p. 2189). This paper indeed provides a mathematically sophisticated and scientifically motivated explanation of how purely individual conceptual spaces can be seen at work. Yet, the authors do also acknowledge that "[w]hat makes communication possible is the capacity to establish similarity-preserving 
mappings between the conceptual spaces of the participants" (Warglien \& Gärdenfors 2013, p. 2181). It seems that this capacity of preserving similarity is still presented, also here, as a necessary or constitutive condition of communication.

We have by now reached an interesting point in our contemplations. Starting from supposed contextual and conceptual worries about formal semantics, formal semantic reflection on a notion of meaning has led to a notion of context, which is a public space, suitably conceived of as a conceptual space-not orthogonal to, but actually and inherently inviting contextual and conceptual exploration. We may then, once again, reflect on the question what it is that we are doing in (formal) semantics? Well, what are we doing with significant verbal behavior? We are inhabiting logical space, or more adequately in the present context, meaning space. As indicated above, such a meaning space can be charted along various dimensions.

Charting the realist or representational dimension of meaning, we observe truthconditional structure, which has been tracked and still is mapped out extensively in the work carried out under the heading of truth conditional semantics.

What formal semantics delivers is a systematic account of broadly 'referential' aspects of meaning. [Under 'referential' we include all those aspects that are analysed in terms of a determinate relationship between expressions and extralinguistic reality (...).] As such that is an essential ingredient of an overall account, since in certain circumstances, as part of certain practices, these are the relevant features that our use of language turns around. (...) From this perspective, then, formal semantics is one methodology that deals with one particular aspect of the heterogeneous phenomenon of meaning. Its contribution to our understanding consists of systematic, conceptual reconstructions of certain aspects of meaning at the idealised level of competence (Stokhof 2013, p. 229).

It has also proven more than worthwhile, of course, to chart the cognitive or conceptual dimension of meaning, the results and insights from which are also very impressive indeed. There is this vast body of work on cognitive grammar and semantics, frames, mental spaces and conceptual spaces. Cf., e.g., (Barsalou 1992, Croft \& Cruse 2004, Fauconnier 2010, Gärdenfors 2000, Lakoff 1987, Langacker 2010). One can of course also track the social, normative, dimension of meaning, which, however, has not been mapped out elaborately yet in formal systems. The main point of all this is that uncovering structure in one dimension of meaning should not need one to exclude any of the others. Of course, I am inclined to add. The insights 
from the various strands of work can be, and better be, brought together as far as is feasible. Warglien and Gärdenfors 2013 provides for an eminent bridge.

Traditional formal semanticists may be worried about the present 'surrenderings' to the contextualist and conceptualist challenges, but this would be unseemly. The assignment of meanings to constituent expressions, and to composite wholes, is not taken to be arbitrary, and the impact of the LPoC itself is built on that assumption. The live meaning of a compound is determined by means of the live meanings of its constituents, and such an argument rests on the assumption that one can make sense of such live meanings of such constituents in the first place. Moreover, the simple idea that, in the interpretation of natural language anything might go, but doesn't go in practice, can be put to work in an assessment of proposals for things that don't go, but, for as far as the LPoC suggests, might have worked out well after all. An example of this can already be distilled from a case discussed above.

In my discussion of the case of the Karamazovs, I qualified example (21) with

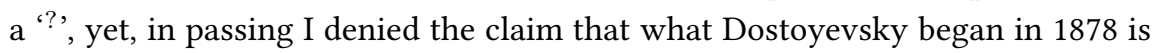
what I finished in 1978. Indeed example (21) should not be deemed infelicitous, but probably false, upon the live interpretation suggested by the description of the case. But this assumes a reading of the example as possibly true, but actually false. False, if, for instance, we can conceive what Dostoyevsky started and what I finished as the onset and completion of one big event. Thus, a literary critic, who thinks very highly of himself, may think of the whole The Brothers Karamazov as one big hoax that he is now concluding by writing the ultimate, killing, review of it-after which nobody is supposed to ever want to read it any more. How unlikely this is, it is not impossible, and if the critic were to state something to that effect using (21), one could very well argue that he said something false - not infelicitous - if one finds out that the discussion about the book still continues. Proper, maybe unlikely, live interpretations of certain constituents may thus render examples which seem to be infelicitous on a first encounter to be felicitous after all.

The case just discussed nicely illustrates a more general, methodological, moral. It is good and customary practice in semantics to investigate certain structural phenomena, by opposing completely unproblematic samples of language with slight variants deemed unacceptable, infelicitous, or 'marked'. It is solid practice to next propose a semantic explanation of the difference, for instance, by blaming the presence or absence of a particular semantic feature or characteristic. The 
concept of live meanings can be called upon to test such explanations. For, a most obvious test of the proposed explanation would consist in setting up a case in which the constituents held responsible for the infelicity in the original examples, are read as having, or lacking, the responsible semantic property. If the proposed explanation runs well, the infelicity disappears in such a case.

Interference Principle If (the absence of) a semantic property $\pi$ of an expression $X$ is to explain the fact that $X$ does not felicitously figure in configuration $* \phi(X)$, then in a context in which the live meaning of $X$ fails (has) $\pi$, it should, all else being equal, render $X$ felicitous in $*(X)$ again.

As a matter of fact, such a test can be and has been applied successfully in specific semantic discussions. (See Dekker 2014 for some more discussion.) If such an interference test is performed, a sceptic might be inclined to see it serve as the disconfirmation of a proposed hypothesis, and the whole test could be considered to ridicule formal semantics. But such a move would be very wrong indeed. As a matter of fact the test may serve to possibly confirm the hypothesis proposed, by, instead, providing the proverbial 'exception that proves the rule.'

Notice that the whole conception of an interference test makes sense only when one allows for a notion of live meanings. For if expressions are assumed to have one literal or linguistic meaning only, then infelicity would be systematic, and ought to be exception free. It may be clear, from the position adopted in this paper, and from the contextualist findings, that such a rigid notion of interpretation had better be given up. Otherwise, as a matter of fact, the principle offers a recipe to disconfirm any semantic hypothesis, rigidly, understood. And that really is a threat for traditional formal semantics.

\section{Conclusion}

I hope I have demonstrated in this paper that a modestly realist, not (yet) theoretically infected, conception of meaning enables one to conceive of meaning as featuring in a public conceptual space. The various (realist, cognitive, social, ...) dimensions of the space can be conceived to be structurally characterized by diverging, possibly orthogonal, theoretical disciplines devoted to that exercise-disciplines which are nonetheless consistent and ideally complementing each other. 


\section{References}

Barsalou, Lawrence W. 1992. Frames, concepts, and conceptual fields. In Adrienne Lehrer \& Eva Feder Kittay (eds.). Frames, fields, and contrasts. 21-74. Hillsdale, NJ: Lawrence Erlbaum Associates.

Borg, Emma. 2004. Minimal semantics. Oxford: Clarendon Press.

Borg, Emma. 2007. Minimalism versus contextualism in semantics. In Gerhard Preyer \& Georg Peter (eds.). Context-sensitivity and semantic minimalism. 339360. Oxford: Oxford University Press.

Cappelen, Herman \& Ernie Lepore. 2005. Insensitive semantics. Oxford: Blackwell. Croft, William. 2010. Construction Grammar. In Dirk Geeraerts \& Hubert Cuykens (eds.). The Oxford Handbook of Cognitive Linguistics. 463-508. Oxford: Oxford University Press.

Croft, William \& D. Alan Cruse. 2004. Cognitive linguistics. Cambridge: Cambridge University Press.

Dekker, Paul. 2014. The live principle of compositionality. In Daniel Gutzmann, Jan Köpping \& Cécile Meier (eds.). Approaches to meaning: Composition, values, and interpretation. 45-84. Leiden: Brill.

Fauconnier, Gilles. 2010. Mental spaces. In Dirk Geeraerts \& Hubert Cuykens (eds.). The Oxford Handbook of Cognitive Linguistics. 351-376. Oxford: Oxford University Press.

Fodor, Jerry A. 2001. Language, thought and compositionality. Mind and Language 16. 1-15.

Frege, Gottlob. 1892. Über Sinn und Bedeutung. Zeitschrift für Philosophie und philosophische Kritik NF 100. 25-50.

Gärdenfors, Peter. 2000. Conceptual spaces: The geometry of thought. Cambridge, MA: MIT Press.

Janssen, Theo M. V. 1986. Foundations and application of Montague grammar CWI Tract 19. Amsterdam: Centre for Mathematics and Computer Science.

Janssen, Theo M. V. 1997. Compositionality. In Johan van Benthem \& Alice ter Meulen (eds.). Handbook of logic and language. 417-473. Amsterdam: Elsevier.

Kripke, Saul. 1979. Speaker's reference and semantic reference. In Peter A. French, Theodore E. Uehling \& Howard K. Wettstein (eds.). Contemporary perspectives in the philosophy of language. 6-27. Minneapolis: University of Minnesota Press. 
Lakoff, George. 1987. Women, fire, and dangerous things: What categories reveal about the mind. Chicago: Chicago University Press.

Langacker, Ronald W. 2010. Cognitive grammar. In Bernd Heine \& Heiko Narrog (eds.). The Oxford handbook of linguistic analysis. 87-109. Oxford: Oxford University Press.

Lasersohn, Peter. 2012. Contextualism and compositionality. Linguistics and Philosophy 35(2). 171-189.

Montague, Richard. 1974. Universal grammar. In Richmond Thomason (ed.). Formal philosophy. Selected papers of Richard Montague. 222-46. New Haven: Yale University Press. Originally published in 1970. Theoria 36. 373-98.

Nunberg, Geoffrey. 1979. The non-uniqueness of semantic solutions: Polysemy. Linguistics and Philosophy 3. 143-184.

Nunberg, Geoffrey. 1995. Transfers of meaning. Journal of Semantics 12. 109-132. Pagin, Peter \& Francis Jeffry Pelletier. 2007. Content, context, and composition. In Gerhard Preyer \& Georg Peter (eds.). Context-sensitivity and semantic minimalism. 25-62. Oxford: Oxford University Press.

Partee, Barbara H. 2004. Compositionality in formal semantics. Oxford: Blackwell.

Quine, W. V. 1948. On what there is. Review of Metaphysics 2. pp. 21-38.

Recanati, François. 1994. Contextualism and anti-contextualism in the philosophy of language. In S. L. Tsohatzidis (ed.). Foundations of speech act theory: Philosophical and linguistic perspectives. 156-66. London and New York: Routledge. Recanati, François. 2004. Literal meaning. Cambridge: Cambridge University Press. Recanati, François. 2005. Literalism and contextualism: Some varieties. In Gerhard Preyer \& Georg Peter (eds.). Contextualism in philosophy: Knowledge, meaning, and truth. 171-196. Oxford: Oxford University Press.

Recanati, François. 2006. Crazy minimalism. Mind and Language 21(1). 21-30.

Speaks, Jeff. 2010/4. Theories of meaning. In Edward N. Zalta (ed.). The Stanford encyclopedia of philosophy. Stanford: http://plato. stanford.edu/.

Stokhof, Martin. 2013. Formal semantics and Wittgenstein: An alternative? The Monist 96(2). 205-231.

Warglien, Massimo \& Peter Gärdenfors. 2013. Semantics, conceptual spaces, and the meeting of minds. Synthese 190. 2165-2193.

Wittgenstein, Ludwig. 1953. Philosophische Untersuchungen/Philosophical investigations. Oxford: Blackwell. 
Live Meanings

\section{Author}

Paul Dekker

University of Amsterdam

ILLC/Department of Philosophy

p.j.e.dekker@uva.nl 
